\title{
Registos "Bio-Gráficos": Uma aproximação ao conhecimento do aluno através do Livro-Objeto proposto por uma professora em construção.
}

\author{
Bio-Graphics" registers: approach to a student's knowledge \\ through the Book-Object proposed by a teacher in probation.
}

\begin{abstract}
Resumo
O presente artigo propõe algumas reflexões acerca do papel do auto-conhecimento do aluno, em contexto de ensino artístico, e de uma pedagogia orientada para a valorização das identidades individuais que consigam desafiar as práticas dominantes. Parece evidente que no atual contexto educativo muitas dessas práticas tendem a ignorar totalmente o sujeito.
\end{abstract}

Estas reflexões têm como pano de fundo a exploração de caminhos e propostas didáticas conducentes a uma prática gráfica regular no Diário Gráfico, nas escolas, recorrendo ao aluno e ao seu património identitário, para a definição do seu próprio registo bio-gráfico autoral.

Palavras-Chave: Desenho; Diário Gráfico; Identidade; Auto conhecimento; Biografia.

\section{Abstract}

The present article proposes some reflections about the role of student self-knowledge in the context of art education, and a pedagogy focused towards the promotion of individual identities that could challenge prevailing practices. It seems clear to everyone that most of that practices tend completely to ignore the subject in the current educational context.

The backdrop of this reflections is the exploitation of paths and didactic proposals leading to a regular drawing practice in Graphic-Diary, at schools, using the student and his identity heritage, to define his own authorial bio-graphic registers.

Keywords: Drawing; Graphic Diary; Identity; Self-Knowledge; Biography. 
Iremos orientar o desenvolvimento deste artigo pelo relato franco e vivencial, que procuramos partilhar, da experiência de campo que tivemos ao contactar com uma turma na disciplina de Desenho A ( $10^{\circ}$ ano, do ensino secundário português, equivalente ao primeiro ano do ensino médio brasileiro), no âmbito da obtenção de grau de Mestre em Ensino das Artes Visuais, em Portugal.

A estrutura que adotei contextualiza o leitor nos diversos passos desta experiência letiva/formativa. Desde a escolha do desafio didático proposto aos alunos, à temática convocada para o seu desenvolvimento, até às conclusões projetadas pelos alunos, como resultado do processo do qual tomaram parte, chegando, por fim, à minha perceção desta experiência educativa.

A viagem é sempre na mesma direção, a aparência disfarça os cenários que se visitam mas a viagem é contínua, até ao interior de mim mesma. Estamos em movimento e o tempo dedicado ao caderno de viagem é a margem de tempo para a reflexão.

Antonia Santolaya (in SALAVISA, 2008, p.58)

Partindo de um sentido reflexivo obtido através da viagem ao nosso interior, e do desenho como seu catalisador, meio de expressão complementar e formalizador de conceitos, ideias ou vivências, trago a este artigo duas linhas de orientação que considero fundamentais no ensino (contexto abrangente), especialmente na prática letiva das Artes Visuais:

- O papel do auto conhecimento do aluno enquanto indivíduo, num contexto social e cultural cada vez mais hegemónico e aparentemente homogéneo.

- Os benefícios educativos que se podem obter através de uma pedagogia vocacionada para a valorização das identidades individuais, num contexto vivencial em que cada vez mais os alunos/sujeitos são tidos pela sua representação e performance quantitativa e não qualitativa.

Sendo a disciplina de Desenho A considerada no Programa Nacional Português de $10^{\circ}$ ano (Programa Nacional de Desenho A 2001, p.3) como estimulante, no que diz respeito ao desenvolvimento estético e no sentido "da qualidade na apreciação ou recriação da forma", é também caracterizada pela possibilidade de ser uma "área de projeção íntima", pela "interiorização da aceitação da diferença e a abertura à inovação, intermediada pelo exercício esclarecido e humanista da sua didática". 
As recomendações pedagógicas do programa desta disciplina orientam também a prática profissional dos docentes para uma "eficiente didática do desenho" através de, entre outras, "Criar hábitos de registo gráfico quotidiano pelo uso de pequenos cadernos portáteis integráveis no arquivo pessoal a constituir;" (Programa Nacional de Desenho A, 2001, p.10).

Tendo em si várias definições, o Diário Gráfico perspetiva-se hoje como uma espécie de herdeiro de séculos de prática gráfica ao longo da história, onde o Desenho foi gradualmente assumindo o seu papel autónomo nos círculos de criação artística. Tenha-se em conta o percurso do Desenho, presente nas práticas artísticas, seja como livro de padrões, livro de modelos, caderno ou álbum de esboços e cadernos de viagem, como foi apontado por Manuel San Payo (2009, p.20). Todavia, foi sobretudo a partir do século XV que o Desenho assumiu o seu caráter de suporte de estudo e experimentação,

" O pequeno caderno ou álbum de esboços fará cada vez mais parte do equipamento habitual do artista, que muitas vezes acumula as funções de ourives, escultor, arquiteto e engenheiro. Neles aparecerão, ao lado de desenhos técnicos, de esboços, exercícios em que se ensaiam soluções para os mais variados problemas, reflexões, apontamentos, recolhas e citações de ideias. O pintor e o desenhador têm nestes cadernos uma ferramenta que os integra nos círculos humanistas e intelectuais letrados dos quais se aproximam socialmente". (SAN PAYO, 2009, p.37)

O Diário Gráfico, considerado como um suporte de registo de memórias visuais, pensamentos e outras experiências pessoais e gráficas, é também um meio de conhecimento do seu autor e da sua dimensão pessoal e íntima. Seja pela linguagem gráfica que apresenta, pela curiosidade técnica desenvolvida, ou pelos assuntos retratados, o Diário Gráfico é um complexo e interessante veículo de informações. Como aponta Eduardo Salavisa (2008, p.14-15), o diário gráfico pode ser entendido como "uma companhia (...) um espaço de liberdade onde tudo é permitido; como um objeto íntimo capaz de receber uma forte carga experimental e criativa". Pode ser interpretado como um "objeto de prazer", no sentido de que guarda em si momentos de contemplação do seu autor perante o que vê, pensa e reflete, ou ainda como forma de comunicação e relação com o outro, aquele que é desenhado e, que dessa forma, se encontra "convocado" pelo desenhador para esta relação circunstancial trazida pelo desenho.

No entanto, as minhas reflexões acerca do Diário Gráfico e, sobretudo, a possibilidade de o podermos construir, fez-me direcionar para outra possibilidade: a do Livro Objeto. 
Sendo um objeto único, pensado e construído, não tem primordialmente em conta a sua funcionalidade (à semelhança do Diário Gráfico), mas o efeito plástico e estético que pode conter em si.

Assim o Diário Gráfico enquanto conceito, agora cruzado, ou coincidente, com o Livro Objeto, apresentou-se rapidamente como opção de trabalho e de exploração gráfica e artística a desenvolver com o grupo de alunos. Ambos como "espaço criativo"; "modo de comunicação com os outros"; "modo de retenção de memória de espaços, pessoas, sentimentos, momentos" (SALAVISA, 2008, p.237), deixavam-me sob a dúvida de qual modelo deveria escolher, e de que forma o poderia abordar. Se seria mesmo possível tratá-los conjuntamente? Qual a sua pertinência na formação do aluno e no seu auto conhecimento, qual a melhor metodologia a seguir de maneira a proporcionar uma experiência significativa (ainda que breve) ao nível plástico e ao nível pessoal.

Tal como refere Ings (2004) pelas palavras de Amy Robinson, artista têxtil, o diário gráfico pode mostrar a progressão de uma ideia, permitindo a contínua exploração visual de um projeto que se pode ver refletido nesse suporte. Refere ainda que o resultado dos diários gráficos pode formalizar experiências pessoais. Também Salavisa (2008, p.28) assim o classifica, afirmando que este está profundamente ligado às informações exteriores, apesar de ter "uma forte carga intimista".

Deveria então procurar uma alternativa aos exercícios "tradicionalmente académicos" de desenho do quotidiano (como sugerido pelo programa da disciplina)? Procurar propor aos alunos que o Diário Gráfico assumisse um papel de "retaguarda" para a melhor compreensão gráfica de alguns exercícios que fossem executados na aula? Ou ainda, propor que o Diário Gráfico pudesse ser "apenas" um espaço para registar e praticar desenho de uma forma livre?

Por um lado, gostaria de encontrar uma proposta que fosse ao encontro dos meus interesses pedagógicos mas que, por outro, também fosse aprazível para os alunos. No fundo, gostaria de produzir nos alunos o que Bruner (1999, p. 65) refere como "um nível óptimo de incerteza" nesta proposta de Diário Gráfico, desejava conduzir os alunos à exploração de alternativas afastadas das suas rotinas.

No seguimento destas questões, tornou-se óbvio que definir as possíveis "identidades" de um Diário Gráfico, assumia um papel prévio tão importante como proceder à proposta de exercícios que pudessem alimentar a sua prática, que pudessem despertar o gosto pela observação, pelo registo e pela reflexão sistemática dos seus contextos, pelo desenho em si e pela sua prática regular. 
Tendo em conta que o contexto académico dos alunos tem por base despertar e ajudar a florescer a criatividade (nos vários ramos que este conceito possa abarcar), tornou-se mais forte a convicção de que, após a uma aproximação ao conceito de identidade atrás referida, deveríamos começar a abordagem ao Diário Gráfico pela construção deste enquanto objeto pessoal. Criar uma "identidade" de raiz, de um modo intencional, talvez fosse a forma de estabelecer laços entre os alunos e os suportes a utilizar para os seus registos gráficos.

Num segundo plano, esta opção assumia em si um outro propósito, o de demonstrar aos próprios alunos que numa contemporaneidade caracterizada significativamente pelo consumismo (onde seria mais fácil e imediato escolher e comprar um bom caderno de desenho), a criatividade e o engenho podem apresentar-se como poderosas ferramentas, seja a favor de projetos artísticos, seja na ultrapassagem dos vários desafios que a vida vai apresentando.

Seguindo a inspiração das palavras de Bruner (1999, p. 64): "uma vez que a aprendizagem e a resolução de problemas dependem da exploração de alternativas, o ensino deve facilitar e regular a exploração de alternativas pelo aluno", vejo em exemplos desta natureza, demonstrados de uma forma continuada, a possibilidade de contribuir para que os alunos criem a confiança necessária em si mesmos, olhem para situações futuras e a visualizem um conjunto de possibilidades mais alargado. Como é referido no Programa Nacional para a disciplina de Desenho A de $10^{\circ}$ ano (2001, p.4):

\footnotetext{
"Na aula de desenho são propostos modos de olhar o mundo capazes de perscrutar as suas aparências e estereótipos. Aqui, como no resto, o papel do professor caracteriza-se pela ação insubstituível, quer nalguma estruturação por «ambiente e contágio» do pensamento e do agir comunicativo, quer pelo que se explora a nível curricular e programático, quer ainda pela ação como criador/autor, gerando ambiente oficinal que se pode caracterizar dentro do chamado «currículo oculto» no melhor dos seus sentidos; e, ainda, evitando inibir potencialidades («currículo omisso ou nulo»)".
}

Assim sendo, surgiu a possibilidade de desenvolver um projeto associado ao Livro Objeto, que não sendo exatamente o primeiro propósito, poderia oferecer uma ponte de continuidade para um futuro Diário Gráfico.

No que concerne à procura da temática, para o desenvolvimento do projeto com os alunos, posso considerar que não foi um processo fácil ou simples. Pretendia simultaneamente que o projeto proposto fosse ao encontro das espectativas dos alunos, de uma forma motivadora e 
enriquecedora para estes e para mim, enquanto futura professora ainda em formação. A prioridade dada às minhas afinidades pedagógicas e didáticas confrontava-se com a cautela necessária na introdução de desafios e com a análise do laço pedagógico (professor da turma / aluno) a que assistia nas aulas de observação.

Sentia que esse laço de conhecimento e proximidade entre os alunos e o professor era estabelecido maioritariamente no campo analítico, intelectualizado e formal, afastando de uma forma geral as particularidades pessoais de cada aluno. Ora como refere Bruner (1997, p. 108):

"(...) o conhecimento de uma "pessoa" não está apenas na sua cabeça, na pessoa isolada', mas nas notas que escreveu em cadernos acessíveis, nos livros com passagens sublinhadas que estão nas prateleiras de alguém, nos manuais que se aprendeu a consultar, nas fontes de informação que se introduzem no computador, nos amigos que se chamam ao telefone para conseguir uma referência, um "rumo" e assim por diante, quase indefinidamente."

Ora, de que forma, nesta relação de ensino/aprendizagem, são construídas as relações entre os professores e alunos? Quais as dimensões que a Escola valoriza ou deverá valorizar neste contexto?

Trazendo Fernando Savater (1997, p.43) ao eixo destas questões, parecia-me, tal como este refere, que "o reconhecimento do ser humano pelo ser humano é um imperativo na via da maturação pessoal de cada um dos indivíduos", que esta era uma aceção fundamental a ter em conta neste desafio que se me avizinhava. Contudo, a proposta que poderia traçar, por ser de cariz mais intimista, trazia-me dúvidas sobre a forma como seria recebida pelos alunos.

Enquanto aluna de mestrado e futura professora profissionalizada, tornava-se mais aliciante aos meus olhos, uma proposta de trabalho que fosse ambivalente, caminhando para o encontro entre o aluno e contexto letivo, valorizando esta dimensão humana através de um trabalho focado no próprio aluno e na sua singularidade.

Este desafio que se avizinhava, ligado a um foro mais intimista, seria bem recebido pelos alunos? Sendo um trabalho focado no próprio aluno, poderia contribuir para uma melhor compreensão do seu universo pessoal por parte do professor (um aspeto que considero especialmente importante, tendo em conta a experiência profissional anterior, enquanto professora contratada)? Contudo, sabia que um ano letivo assumia-se como um espaço cronológico muito limitado para o estabelecimento de relações e para um conhecimento mais profundo dos alunos como defendo na minha filosofia de ensino. Entendo que o professor não 
se pode cingir apenas aos conteúdos específicos da sua área de ensino, pelo contrário, deve ser colocado numa complexa relação em que as perceções têm de estar afinadas, de forma a compreender cada aluno nas suas potencialidades, limitações, ansiedades, interrogações e expressividade própria, como refere Paulo Freire:

"Os professores não ensinam apenas conteúdos. Através da sua prática, também ensinam como pensar criticamente. Se somos progressistas, então ensinar, para nós, não é depositar pacotes de conteúdo na consciência vazia dos alunos." (APPLE \& NóvOA, 1998, p.55)

Embora não tivesse o que posso honestamente referir como uma sólida relação de confiança mútua, consegui criar alguns laços de um certo "à-vontade" e de curiosidade por parte dos alunos, sobre o que Ihes traria de novo, facto que me deu o encorajamento necessário para formalizar o tema que seguidamente explico:

Desde há muito que a temática das histórias de vida, as questões da identidade individual e coletiva e as biografias me suscitavam particular interesse. Como refere Polak (1989) citado em Fernandes (2002, p.82):

"a reconstrução a posteriori da história da vida ordena acontecimentos que balizaram uma existência" e, (...) através desse trabalho de reconstrução de si mesmo, o indivíduo tende a definir seu lugar social e suas relações com os outros"

Mas olhando mais para trás, percebemos que as questões identitárias surgiram inevitavelmente associadas à modernidade. Primeiramente pela necessidade de definição da identidade (por questões essencialmente administrativas), posteriormente esta necessidade assumiu um nível intelectual mais profundo, segundo Jean-Claude Kaufman (2005, p. 17-28) um indivíduo integrado na comunidade não coloca as mesmas questões que os indivíduos que são oriundos de comunidades desestruturadas. Estas "fornecem" ao individuo o seu sentido de crise pessoal: a dificuldade na definição de si mesmo.

A identidade não pode então ser vista isoladamente ou sobre a forma de um "produto" final. 0 processo da criação desta, conta inevitavelmente com a intervenção e apropriação do ambiente social dos indivíduos, como refere Kaufman (2005, p. 24-30): "O indivíduo estrutura o seu eu por meio de trocas identificatórias com o que o rodeia, interiorizando modelos e imagens.", ou como advoga Mead (1963) citado pelo mesmo autor, " O indivíduo é social, ele próprio profundamente marcado por um contexto histórico preciso. Nenhum destes três elementos (indivíduo, sociedade, história) deve ser separada na análise". 
Ora com a modernidade e com a crescente individualização da sociedade e homogeneização identitária1 ${ }^{1}$ coloca-se-nos uma certa "confusão" latente, originária na profusão de referências, modelos e imagens.

Formalizando estas preocupações e transportando-as para esta experiência letiva, coloquei a hipótese de que esta proposta pudesse assumir o papel de uma possível "iniciação" destes alunos da área artística, através da viagem à definição da sua própria identidade, do si mesmo "(...) como um guardião da permanência e como um barómetro que corresponde ao tempo cultural local." (BRUNER, 1997, p.111).

À parte do âmbito relacional professor/aluno, pretendi com esta escolha que a presente temática pudesse contribuir para uma auto afirmação dos alunos, enquanto sujeitos, e para o processo de construção dos seus caminhos e escolhas pessoais, tal como aponta João Loureiro (1990, p.25):

"A ação educativa deve orientar-se no sentido da descoberta, de levar o educando a conhecer-se a si próprio para se assumir em liberdade e responsabilidade como pessoa e, no mesmo contexto, assumir os outros. É o sentido positivo da personalização."

O "conhecer-se" para conhecer melhor o outro, e o conhecer o outro como forma de se conhecer a si próprio (FRANÇA, 1981, p. 8), assumia um papel cada vez mais relevante.

Para além do interesse "investigativo" que me movia, relativamente às histórias de vida, não me foi alheio o facto da entrada para o ensino secundário representar para muitos alunos uma mudança de escola, a escolha de uma área de estudo mais específica, novos professores e colegas que conduzem a uma fase de adaptação e a um terreno desconhecido.

Por outro lado, existia ainda outro fator importante a considerar: a adolescência como "terreno de construção" identitária que lhe está inerente.

Recuando ao meu fundo biográfico e às memórias de que disponho para poder ver, comparar, refletir e criar pensamentos acerca do que me inquieta e do que me inspira atualmente (ainda que estes sejam fruto da minha "grelha percetiva" e dessa forma também auxiliem na minha definição identitária), a minha passagem pelo Ensino Secundário (que também tomou lugar na mesma escola, com os mesmos professores e com a mesma rutura de contexto) reavivou-me a importância dos meus próprios diários gráficos e das motivações que me moviam, as imagens que me surgiam e despertavam particular interesse.

\footnotetext{
1 - Tenha-se como exemplo as possíveis identidades que um indivíduo pode criar no meio internético, ou a importação das mais variadas referências culturais, que lhe chegam diariamente pelos meios de comunicação.
} 
Percebi com essa viagem ao passado, que o tempo subsequente me trouxe uma espécie de "revivalismo" cíclico de interesses e ideias para projetos posteriores, dando forma ao que Bruner (1997, p.111) refere como a "deslumbrante capacidade intelectual de visionar alternativas - conceber outras maneiras de ser, de agir, de lutar. Assim, embora sejamos em certo sentido criaturas da história, somos, noutra acepção, também agentes autónomos".

Este sentido de uma narrativa, como refere Ricoeur, que ordena os acontecimentos e dá sentido à ação (KAUFMANN, 2005) atua sobretudo na compreensão do sítio de onde parti, desse ponto de início face ao ponto onde atualmente me situo. O resultado desse percurso traz-me um auto conhecimento precioso e fundamental como balanço do percurso que tenho vindo a desenvolver pessoalmente. Aquilo a que Bruner se refere como "reflexividade humana", a nossa capacidade de alterar passados e presentes pela reflexão e comparação dos mesmos, a possibilidade de evocar e dar significados ao passado e relacioná-los com a contemporaneidade para poder perspetivar o futuro. Pelas palavras de Fernandes (2002, p.8283):

o "(...) passado, presente e futuro, estão interligados e que o sentido de reconstrução do passado é dado pelo presente (que o reinterpreta) e essa reconstrução vai reorientar futuras ações. Assim, esses três tempos não são simplesmente continuidades cronológicas, mas se auto-influenciam em um encadeamento de sentidos e significados.".

Ponderando todos argumentos, a minha intuição didática e vontade pedagógica levou-me a esboçar o tema que apresentei à turma, "Registos Bio-Gráficos", iniciado pelo auto-retrato.

Uma vez que procurava criar uma ponte para a futura utilização do diário gráfico, que comporta uma dimensão exploratória livre e pessoal, sentia que de certa forma, esta imposição inicial desvirtuava um pouco os objetivos que visionava alcançar. Por outro lado, não me identificando com uma pedagogia marcadamente impositiva ao nível temático (num contexto de educação artística), também compreendia que, como refere Savater (1997), aquilo que constituirá o "homem maduro" ainda se encontra fortemente sedimentado no aluno e que, no exercício das suas funções, o professor tem o dever de propor ao aluno projetos que Ihe possam trazer autonomia; virtudes sociais; disciplina intelectual. Também Elisabete Oliveira (2010, p. 33) nos remete para este sentido, referindo que "(...) o professor será um organizador de referenciais maturados pela reflexão e/ou a experiência, adequados ao nível de desenvolvimento e necessidades da diversidade dos alunos, em forma que Ihes permita opção e auto-organização no contexto educativo-cultural." 
Neste contexto, e em virtude da presença formativa do Professor, o aluno tem a possibilidade de aceder a diferentes referenciais alternativos. Talvez estes mais "genuínos e sinceros" no que respeita ao interesse pelo desenvolvimento intelectual e humano do aluno/pessoa. Tenhamos em consideração que os alunos se encontram diariamente expostos aos mais variados referenciais, e ainda que estes sejam massivamente enaltecidos em diversos canais de comunicação, também atuam como elementos formativos, não significando necessariamente os melhores exemplos a seguir.

A reforçar esta ideia, Savater (2010) aponta que os contextos culturais e tecnológicos sofrem, cada vez mais, alterações a um ritmo acelerado, quer a televisão como o computador (e a internet), trazendo milhares de informações às crianças e jovens, colocando aos professores uma dificuldade adicional ao seu processo letivo: de que forma o professor pode auxiliar os seus alunos na criação de "ferramentas intelectuais" que Ihes permitam triar e organizar as informações que recebem?

Tendo em conta que a escolaridade comporta em si, como refere Bruner (1996), a indução de "quadros canónicos culturais" nos jovens, a escola enfrenta constantemente uma "disputa" na veiculação de referências perante outros meios de "indução cultural dos seus alunos". E, nesse sentido, como refere o autor acima citado, dever-se-á ter bem presente, de uma forma esclarecida, quais os objetivos sociais que se pretendem atingir através da escolaridade.

Neste caso particular, considerei que seria positivo introduzir um certo parâmetro impositivo relativamente ao tema, uma vez que este poderia assinalar o início de um percurso auto crítico e reflexivo, duas das competências que me parecem fundamentais ser trabalhadas no âmbito da escola. Por outro lado, sabia que o auto-retrato (que aqui se apresentava como uma introdução a um registo "bio-gráfico" mais alargado no tempo) constituía um dos itens temáticos a desenvolver ao longo dos três anos curriculares da disciplina de Desenho A e, por esse motivo, para além de desenvolver um projeto relacionado com os conteúdos programáticos da disciplina, antecipávamos a sua introdução.

\section{Desenvolvimento da unidade didática}

Uma das obsessões da minha adolescência era pôr em papel tudo o que me rodeava e interessava, para criar uma espécie de enciclopédia pessoal.

José Maria Sanchéz (in SALAVISA, 2008, p. 132) 
A preparação da apresentação deste projeto assumiu duas frentes, a apresentação do projeto de construção do Livro Objeto e dos materiais atuantes e a apresentação do tema "Registos Bio-Gráficos".

A primeira, apresentada aos alunos através de um breve percurso histórico acerca da importância do livro, desde o aparecimento da escrita aplicada nas estelas; placas enceradas; papiros; volumen e códices; ao aparecimento do papel e sua importância na difusão e circulação de cópias de obras, até ao atual E-book. Esta apresentação avançou o espaço necessário para introduzir "livros" relacionados com a prática artística, refiro-me ao que Salavisa (2008) define como Livro de Artista, Livro Objeto e Diário Gráfico.

Para complementar os conteúdos expostos, considerei útil apresentar alguns exemplos "físicos" de vários objetos associados ao tema: Livros antigos; Diário Gráfico e Livro Objeto.
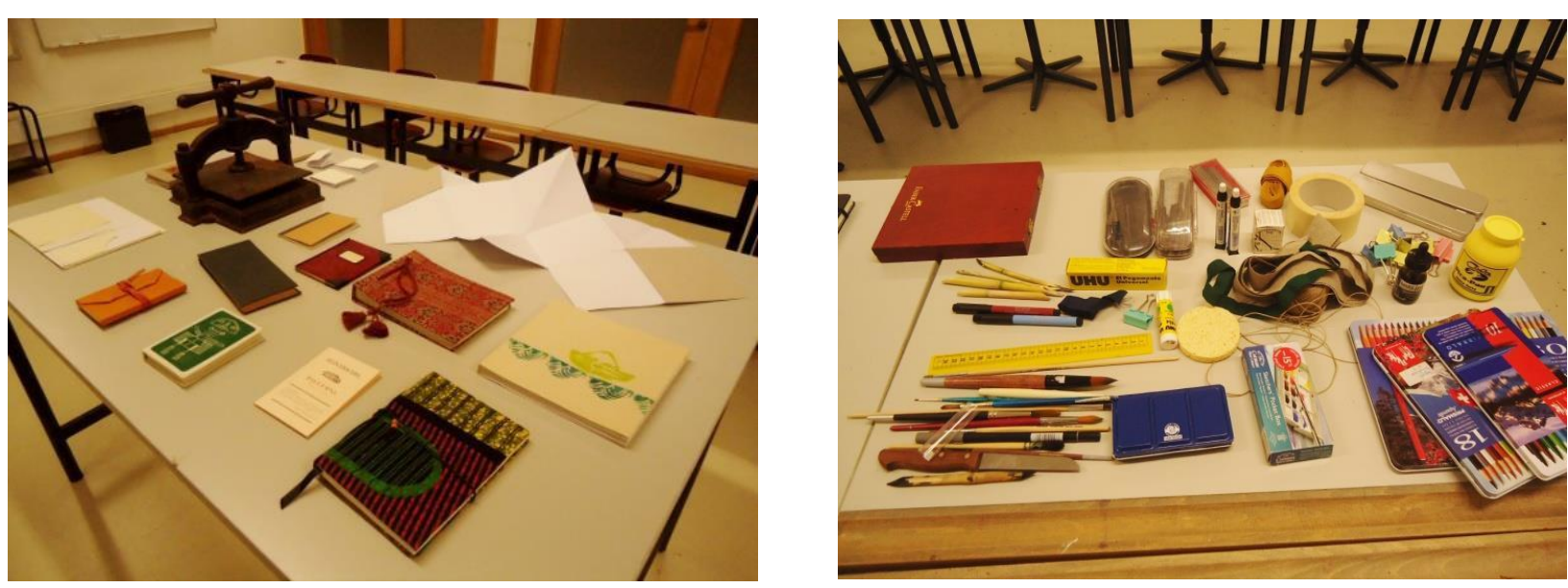

Figura.1- Alguns exemplos de Diário Gráfico, Livro Objeto e materiais para registo gráfico

(Foto da autora)

Procurei assim incutir, na preparação da apresentação, um certo "espírito oficinal", como aliás é recomendado no programa nacional de Desenho $A$, para que desta forma, os alunos tivessem várias referências visuais, estéticas e técnicas, para que mesmo num contexto de sala de aula, pudesse surgir a mediação de vários mundos e temas mediante a utilização de objetos cuidadosamente selecionados. Como refere Oliveira (2010, p.32): 
"(...) a intervenção do professor será não a de modelizar mas a de comunicar experiências ao aluno que ele elaborará (...) que ele ainda terá de transformar para incorporar a sua síntese; pelas quais ele se auto-modele, assumindo crescentemente a direção de projetos."

Uma vez que tinha optado pela criação de um Livro Objeto, realizado pelos próprios alunos, propus também uma dimensão "oficinal" estendida à construção de um instrumento de trabalho: o aparo.

A escolha de materiais recaiu sobre meios atuantes secos e aquosos, como é o caso da grafite e tinta-da-china preta e, como instrumentos de trabalho, aparo de cana e pincel (constantes na lista de materiais a ser explorados ao longo dos três anos).

Reportando-me à prática profissional de anos anteriores, tinha observado que os alunos consideravam curioso o facto de serem os próprios artistas a executar alguns dos seus materiais e instrumentos de trabalho.

Ao nível da proposta conceptual, projetei uma apresentação do tema "Registos Bio-gráficos" através da recolha de um conjunto de imagens que ilustrasse o papel fundamental do Desenho e do Diário Gráfico na maturação de ideias, e no sentido projetual inerente à prática artística.

Dentro das opções que considerei, selecionei imagens de Henry Moore, Edward Hooper, Hyeronimus Bosch e Frida Kahlo. Esta seleção teve como objetivo proporcionar aos alunos uma breve visão dos trabalhos plásticos destes autores e enriquecer a sua cultura artística ao nível da história da arte. Com esta escolha, procurei também introduzir a transversalidade de linguagens artísticas, associadas a diferentes nacionalidades e contextos cronológicos. Por esse motivo, acrescentei a esta seleção uma secção dedicada aos sketchbooks, pela sua atualidade e veiculação dentro de expressões associadas à Street art e ao Graffiti e, por fim, os registos gráficos associados a uma banda desenhada em especial.

Encontrei, no trabalho gráfico de Marjane Satrapi, um ponto comum com o que me proponhamos desenvolver com os alunos. Sendo "Persépolis" um trabalho auto biográfico que me suscitou particular interesse, primeiramente enquanto livro de banda desenhada (graphic novel) e posteriormente como filme de animação (que mereceu a atenção mundial dos críticos e do público, tendo ganho o prémio do Júri no festival de Cannes em 2007, e tendo estado proposto para um Óscar). Encontrei nele a pertinência e o reconhecimento necessários para constar como exemplo a partilhar com os alunos.

O trabalho de Satrapi demonstrava não só a sua história pessoal (da infância à idade adulta), como também um retrato histórico crítico, ao nível das mudanças políticas e sociais que se podem presenciar no Irão (o seu país natal). Nunca deixando de lado a sua voz pessoal e 
feminina acerca destas mudanças, o filme que partilhei com os alunos, demonstrava claramente que o desenho ao "serviço" de um sentido crítico e de uma observação perspicaz e informada, pode ser um veículo de informação e de partilha vasto e enriquecedor.

Este exemplo trouxe-me a certeza de que o desenho e a autobiografia, além de atuar como testemunho pessoal (pelo mapeamento e reservatório das particularidades do sujeito), trazem à esfera exterior a possibilidade de compreender os contextos sociais, culturais e políticos, de uma forma vivida na primeira pessoa.

No limite, o valor autobiográfico pode associar-se, por analogia, à "continuidade da espécie humana", reportando-se à continuidade das nossas experiências, reflexões e emoções, no tempo e no espaço geográfico, inspirando e incitando outros seres humanos ao seu próprio mapeamento e localização.

Após a abordagem teórica do assunto a tratar, os alunos foram levados a momentos introspetivos de reflexão sobre si próprios e a começarem os seus registos bio-gráficos através do registo do rosto ${ }^{2}$. Neste exercício foram incluídas dimensões percetivas dos volumes, desenho de memória, desenho cego e desenho de observação.

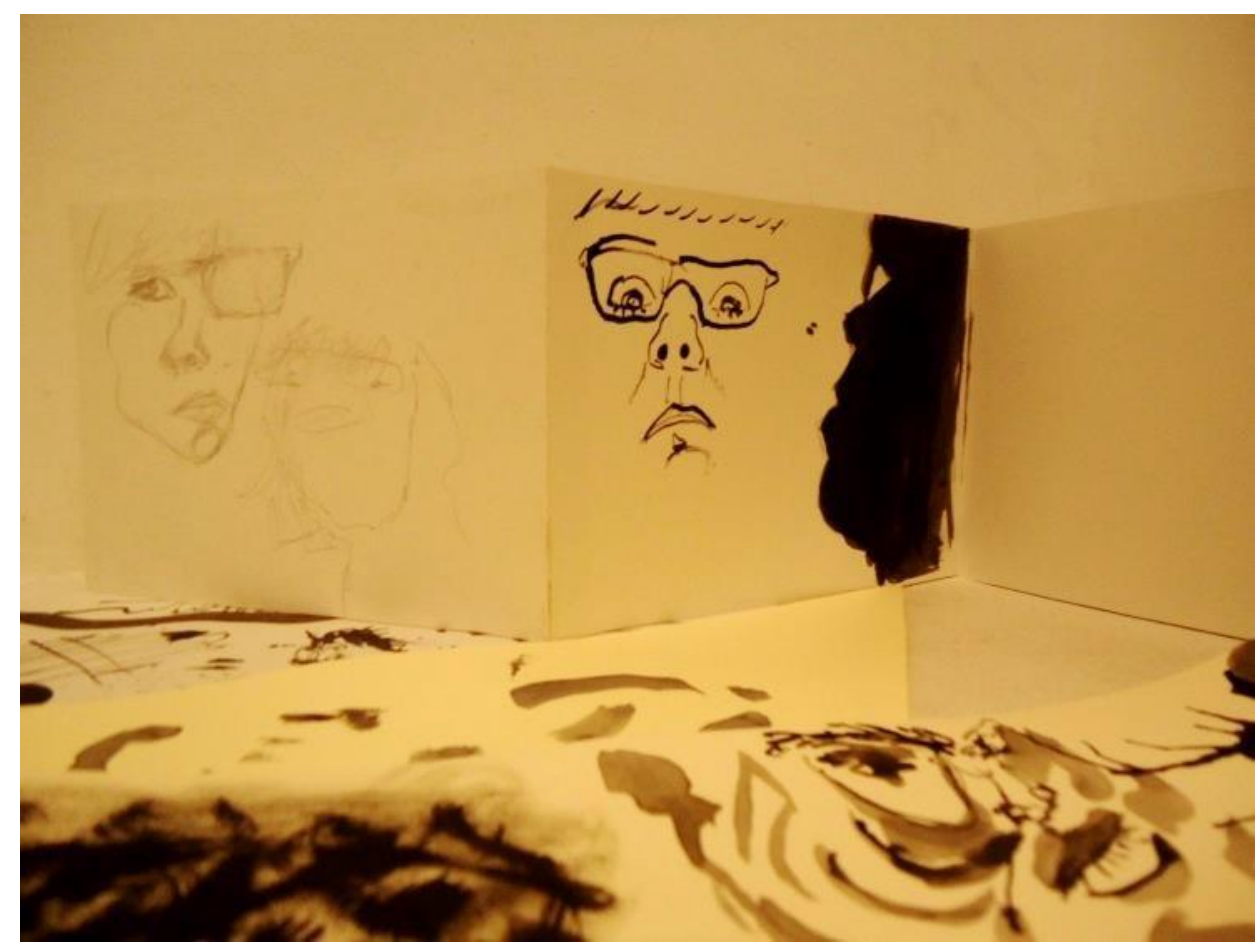

2 - Tendo em conta os últimos processos de identificação dos indivíduos, em que número associados ao sistema de saúde; carta de condução; segurança social; etc., figuram a par com o rosto fotografado. Este último item cumpriu o propósito de, trazer aos projetos individuais dos alunos, o elemento identificador necessário que remetesse para quem executou o trabalho, bem como o momento cronológico em que o seu executante os levou a cabo (adolescência). 

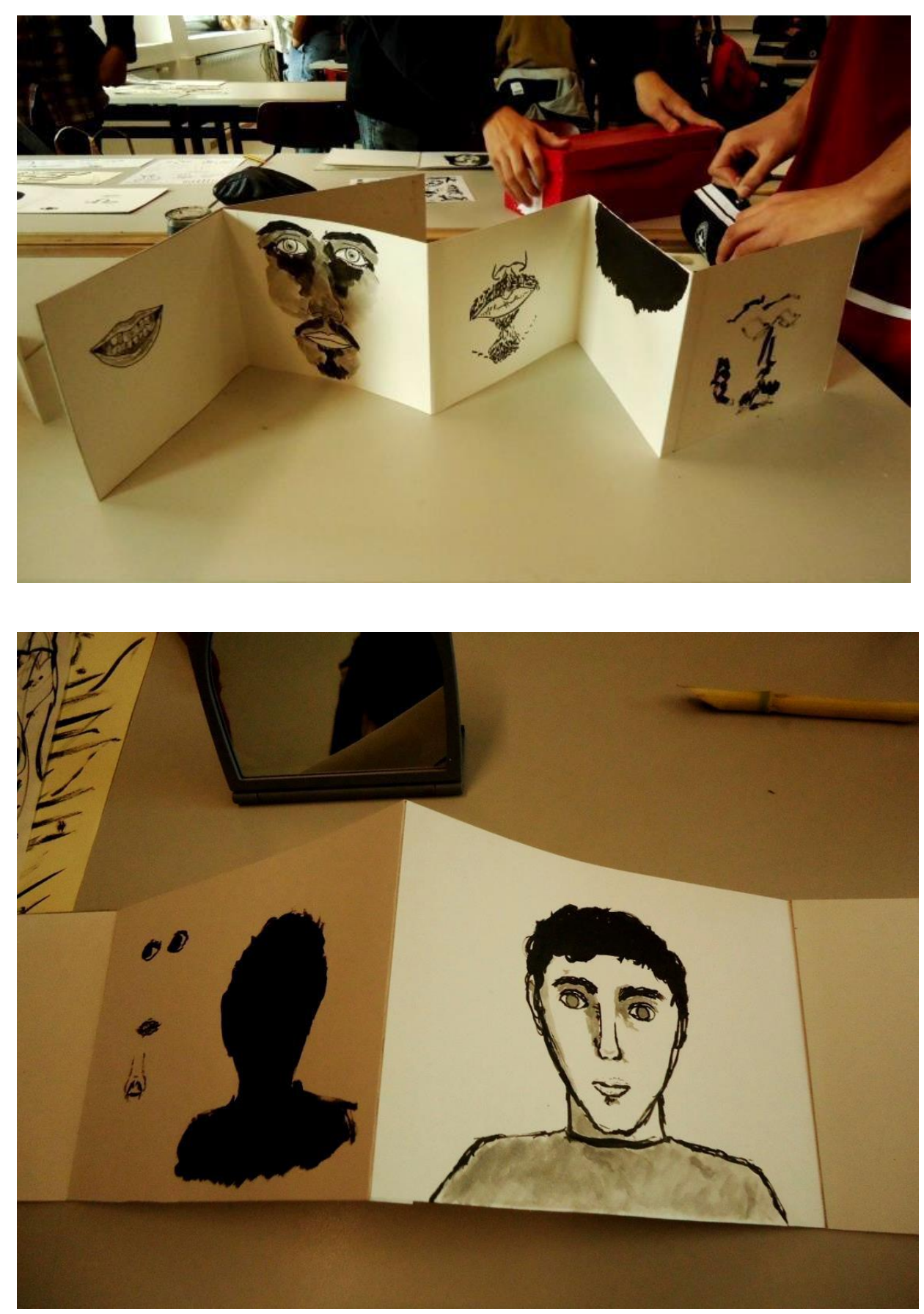

Figura.2- Exercício de auto-retrato dos alunos a tinta-da-china (Foto da autora).

Foi ainda acrescentada a possibilidade dos alunos escolherem elementos constituintes dos seus rostos, os quais fossem da sua preferência, e dessa forma pudessem ser alvo de destaque 
através do Desenho. Os exercícios, como já foi referido, foram executados a grafite; tinta-dachina preta; aparo; pincel e espelho.

Posso considerar que os projetos tiveram uma implementação positiva junto dos alunos, trazendo a estes a direção para uma prática continuada, que mesmo podendo não encontrar sentido na motivação de todos os alunos, trouxe em si a possibilidade de conhecimento de outras propostas, possibilidades e caminhos, o início de um objetivo a longo prazo. Esta dimensão, que não pode ser relatada como resultado quantificável, numa avaliação nominativa, talvez traga os seus ecos enquanto plataforma de descoberta e crescimento interior (informações que só o tempo e a maturação dos alunos poderá confirmar).

\section{Considerações dos alunos}

Como forma de aferir elementos que melhor me ilustrassem as perceções dos alunos relativamente à experiência pela qual passaram, pedi a estes que preenchessem de forma objetiva e anónima, um questionário de apreciação do projeto, a nível da tipologia e dos materiais didáticos utilizados; o envolvimento do aluno nas fases de construção do Livroobjeto, experimentação de materiais e nos registos efetuados no mesmo e a pertinência do Livro-Objeto na utilização futura do Diário Gráfico.

Relativamente à "utilidade" da observação e contacto com os diários gráficos; livros-objetos e outros materiais levados como exemplo, os alunos referiram que o contacto com os mesmos foi útil, uma vez que muitos não conheciam os conceitos intrínsecos à natureza de ambos e, que desta forma, puderam compreender a diversidade de exemplos que os caracterizam. Valorizaram questões relacionadas com a liberdade de temáticas representadas, as quais puderam apreender dos exemplos que visualizaram, tal como questões estruturais relativas à construção do próprio diário ou livro-objeto. Por outro lado, identificaram a presença e contacto físico com os objetos didáticos, de máxima importância, uma vez que facilita o processo de aprendizagem, trazendo outras referências visuais, e auxiliando na construção de ideias e linguagens próprias.

Tal como foi referido por Paulo, um dos alunos:

"Sim, acho que foi importante nos terem mostrado vários diários gráficos, porque primeiro a maior parte das pessoas não sabia o que era nem como eram feitos e com a apresentação de alguns diários gráficos ficámos a saber que há muitas maneiras de fazer este diário gráfico e que o podemos fazer com qualquer coisa, mas ainda mais 
importante é que podemos desenhar tudo o que quisermos e percebemos isso com a observação de alguns diários gráficos.",

ou como foi apontado por Mário,

" Sim, porque passámos a ter uma ideia do que são diários gráficos, livros-objetos, e que neles podemos nos exprimir de forma livre aquilo que sentimos, ou seja, podemos neles escrever/ desenhar tudo o que quisermos."

Pude reter que alguns dos alunos sentiram dificuldades na criação do livro-objeto, uma vez que não estão muito familiarizados com a componente de construção manual. Este processo, trouxe aos alunos, a possibilidade da experiência de construção de um suporte onde desenhar, em que, como foi referido, podem registar graficamente "coisas mais pessoais". Por outro lado consideraram ser uma experiência importante, uma vez que os alunos referiram ter percebido as várias fases de construção do livro. À parte da dimensão estrutural da construção do suporte, a importância dentro do domínio afetivo foi também referida, tal como pude ler pelas palavras de Ricardo, um dos alunos:

"Sim porque foi algo pessoal e a que temos agora uma espécie de ligação, visto que somos nós os criadores do nosso diário e não apenas do seu conteúdo."

Tal como a construção aproxima os alunos de um material por eles produzido, dando lugar ao laço afetivo entre "o criador e a obra", também a personalização do livro-objeto, além de trazer o aspeto visual de um trabalho finalizado, mostra a individualidade de cada livro-objeto, contribuindo para que cada um seja único, "o livro deixa de ser um objeto comum e passa a ser especial e ainda mais pessoal".

Todos os alunos referiram ter-se envolvido de uma forma significativa na unidade didática. Indicaram as experiências com os materiais e instrumentos, nos exercícios gráficos efetuados, como fatores de maior agrado. Destacaram o aparo de cana e a tinta-da-china como material e instrumento (com os quais os alunos nunca tinham trabalhado), alguns alunos referenciaramnos pela diferença de efeitos plásticos que com eles podiam obter.

Relativamente aos exercícios efetuados, referiram novamente a experiência com os materiais, como é exemplo o testemunho de Ana: "Com a tinta da china porque senti muita liberdade no que eu poderia fazer no papel (para mim uma das melhores aulas)", tendo ainda mencionado o caracter dos exercícios desenvolvidos e as dificuldades neles sentidas: 
"No trabalho onde tínhamos de olhar para o espelho e desenharmonos, porque foi um desafio porque normalmente só desenho pessoas através de fotos e faze-lo a partir de um vidro (espelho) foi complicado".

Na apreciação dos registos gráficos efetuados, percebi que os alunos focaram a sua atenção na "novidade" da tipologia dos exercícios levados. Refiro-me aos "registos de aquecimento" que foram feitos antes do desenho de observação mais demorado. Embora revelassem que o resultado destes não havia sido "perfeito" e que tinham representado dificuldade técnica, tal como pude constatar: "Gostei, claro que não saíram perfeitos mas o objetivo e mesmo tentativa erro para irmos melhorando com o tempo.", por outro lado, revelaram que os resultados obtidos foram interessantes e diferentes, "(...) Como tínhamos que nos desenhar a nós próprios o trabalho realizado tornou-se ainda mais pessoal, mas agradável" (Isabel).

Os alunos referiram que o livro-objeto Ihes trouxe motivação para desenhar no mesmo, uma vez que foram os próprios a construí-lo, e que, por essa razão, têm-Ihe maior "respeito" e sentido de preservação.

Viram esta experiencia formativa, como uma iniciação ao diário gráfico, e às suas potencialidades temáticas e expressivas. Este conta com uma prática regular de desenho, menos preocupada, capaz de albergar a expressão de sentimentos a par das técnicas e materiais utilizados, " (...) serviu para ver o que pode ser o nosso diário gráfico, um sítio onde nos podemos expressar de uma forma muito própria. (Vanessa)". Sendo um espaço de "treino", passou a ser visto como um caminho de aperfeiçoamento dos registos, de evolução e de inspiração para projetos futuros.

Como forma de concluir a apreciação dos alunos, encontrei três respostas que me parecem ilustrar a perceção dos alunos, quanto à importância do desenho e da sua prática em diário gráfico:

"Cada vez que se pratica um desenho, começa-se a melhorar cada vez mais o desenho e assim é bom a prática do desenho no diário gráfico."

"(...) Porque no diário gráfico podemos desenhar sem medo e sem a preocupação de desenhar bem e com o tempo vamos evoluindo."

"Dá-nos um à vontade a desenhar e quanto mais desenharmos mais imaginação temos e criatividade." 


\section{Considerações finais}

Deixando-me "contagiar" pelo sentido de registo biográfico, que abordei ao longo deste artigo, vejo-me agora no processo de "seleção" e de atribuição de "importâncias", ao que compõe o meu contexto profissional atual. Nele, encontro presente as preocupações do XIX Governo Constitucional Português quanto à "promoção do sucesso escolar, a redução da dispersão curricular nos 2.0 e 3.0 ciclos, o reforço da aprendizagem em disciplinas estruturantes, como a Língua Portuguesa e a Matemática", e à proposta-base da revisão da estrutura curricular, apontados por Nuno Crato (2012) como pensadas para "centrar mais o currículo nos conhecimentos fundamentais e reforçar a aprendizagem nas disciplinas essenciais", sendo estas identificadas como "História, Geografia, Físico-Química e Ciências Naturais".

As preocupações dos professores de artes visuais e de outras expressões talvez sejam fruto destas inquietações que agora podemos ver espelhados, num artigo recentemente publicado por um periódico português, através das palavras de Leonel Moura (2013, p.30):

" (...) a sociedade evoluiu no sentido da complexidade, como não poderia deixar de ser, mas sem garantir ao mesmo tempo algumas regras base de comportamento como sejam a honestidade, a transparência, o sentido de serviço público, a procura de bem-estar e de felicidade".

Num sentido geral, estes fatores já se revelam preocupantes no que respeita à identificação de uma crise de consciência humana, moral e política, colocando em causa a civilização criada pelo Homem. Atualmente, como se sabe, o contexto educativo em que estamos inseridos aclama a competitividade dos indivíduos, e enaltece a formação científica (como se pode constatar pela identificação das disciplinas ditas "fundamentais"). Esta formação científica é tida como o meio para atingir resultados de excelência, numa sociedade de futuro.

Será o apologismo dos valores científicos e de uma sociedade tecnocrata o caminho que a escolarização deve seguir, e prestar como referencial à formação de alunos (futuros "competidores")?

Ou, à parte da uniformidade da civilização tecnológica, devemos encontrar uma escolarização orientada para um equilíbrio entre a tecnologia e o indivíduo, onde este e a sua identidade cultural e pessoal, tenham espaço de desenvolvimento num currículo escolar?

Considero que a temática explanada na proposta didática que desenvolvi enquanto professora em formação, consegue dar "a minha" resposta a esta interrogação. Esta assumiu-se como 
metáfora para a criação de um caminho entre as preocupações da minha agenda pedagógica e as questões didáticas a ela referentes, deixando vislumbrar a importância das disciplinas artísticas (neste caso o Desenho A), na maturação do auto conhecimento dos alunos.

Se "Nós somos o que partilhamos" (LEADBEATER, 2009) como também prefiro pensar, então a Escola, a par de tudo, deve ensinar os seus alunos a valorizar o que são e o que representam no mundo, a Escola deve ensinar os alunos a serem pessoas, conhecedoras de si próprias (antes de uma promoção à alta intelectualidade e competitividade, independentemente de que área for), a serem críticas e criativas, a terem consciência da sua cidadania, dos seus deveres e direitos e da repercussão dos seus atos e decisões, a saberem partilhar com a mesma generosidade com que recebem. Tal como refere Teresa Eça (2008, p.7) "(...) evoco a pedagogia construtivista para fazer cidadãos."

Deste modo a Escola também permitirá aos professores, preparar os seus alunos para o "sucesso", não num sentido passível de ser medido diretamente numa carreira profissional dita de "excelência", mas sim numa vivência colaborativa no dia-a-dia, nos atos de partilha de valores éticos e morais, com a firmeza de uma personalidade ciente de si a par da existência de tantas outras.

\section{Referências}

APPle, M. \& NóvOA, A. (org.). Paulo Freire: Política e Pedagogia. Porto: Porto Editora, Lda, 1998

BRUNER, J. Cultura da Educação. Lisboa: Edições 70, 1996

BRUNER, J. Actos de significado, para uma psicologia cultural. Lisboa: Edições 70, 1997

BRUNER, J. Para uma teoria da educação. Lisboa: Relógio d'água editores Ida., 1999

FRANÇA, A. O retrato na Arte Portuguesa. Lisboa: Livros Horizonte, 1981

INGS, R. Creating Chances, Arts intervenyions in Pupil Referral Units and Learning

Support Units. London: Calouste Gulbenkian Foundation, 2004

KAUFMANN, J. A invenção de si, uma teoria da identidade. Lisboa: Instituto Piaget. 2005 
LOUREIRO, J. À procura de uma Pedagogia Humanista. Lisboa: Instituto Nacional De Investigação Científica, 1990

MOURA, L. (2013). Mandelas. Jornal de Negócios, 13 de Dezembro de 2013

OLIVEIRA, E. Educação Estética Visual Eco-necessária na adolescência, sete Décadas design curricular em Portugal. Coimbra: Minerva Coimbra EDIÇÕES, 2010

SALAVISA, E. Diários de Viagem, desenhos do quotidiano, 35 autores contemporâneos. Lisboa: Quimera Editores, 2008

SAN PAYO, M. O Desenho em viagem: álbum, caderno ou diário gráfico. 0 álbum, de Domingos António de Sequeira. Tese de doutoramento em Belas Artes/Desenho. Lisboa: Universidade de Lisboa, Faculdade de Belas Artes de Lisboa, 2009.

SATRAPI, M. Persépolis 1. Lisboa: Edições Polvo, Lda., 2003.

SAVATER, F. O valor de educar. Lisboa: Editorial Presença, 1997.

SAVATER, F.\& CASTILLO, M. \& CRATO, N.\& DAMIÃO, H. O valor de educar, o valor de instruir. Lisboa: Fundação Francisco Manuel dos Santos, 2010

EÇA, T. Para acabar de vez com a educação artística.

n. 1 (1): Revista Digital do LAV - Ano I - Número 01 - Setembro de 2008

in:http://cascavel.ufsm.br/revistas/ojs2.2.2/index.php/revislav/search/authors/view?firstNa $m e=$ Teresa\&middleName $=$ Torres\&last Name $=E \% C 3 \% A 7 a \&$ affiliation $=\&$ country $=$ FERNANDES, R. Memórias de Menina. Cadernos CEDES, ano XXII (Scielo Brazil The Scientific Electronic Library Online) in:

http://www.scielo.br/pdf/ccedes/v22n56/10866.pdf

(2002, consultado a 7 de Janeiro de 2012)

RAMOS, A. \& QUEIROZ, J. \& BARROS, S. \& REIS, V. Desenho A, $10^{\circ}$ Ano, Curso Científico Humanístico de Artes Visuais. Ministério da Educação, Departamento do Ensino Superior in:

http://www.dgidc. minedu.pt/ensinosecundario/index.php?s=directorio\&pid=2\&letra=D (2001, consultado a 10 de Outubro de 2011) 
Diário da República, 1.a série - N.0 148 - 3 de Agosto de 2011

in: http://dre.pt/pdf1sdip/2011/08/14800/0414204150.pdf

(2011, consultado a 19 de Janeiro de 2012)

Lusa. Revisão curricular tem sido "muito bem acolhida" garante Nuno Crato.

Jornal Público in: http://www.publico.pt/Educa\%C3\%A7\%C3\%A30/revisao- curricular-temsido-muito-bem-acolhida-garante-nuno-crato--1529701

(2012, consultado a 19 de Janeiro de 2012)

Direção-Geral de inovação e de desenvolvimento curricular. Revisão da estrutura Curricular.

in: http://www.dgidc.min-edu.pt/

(consultado a 20 de Janeiro de 2012)

LEADBEATER, C. Charles Leadbeater: Somos o que partilhamos (vídeo).

Jornal Expresso in: http://aeiou.expresso.pt/charles-leadbeater-somos-o-que-partilhamos video $=f 548375$

(2009, consultado a 10 de Janeiro de 2012)

SATRAPI, M. \& PARONNAUD, V. Persépolis (filme), 2007

Daniela Bacalhau

Universidade de Évora, Portugal

Email: dodfish@gmail.com

Recebido em: 11/02/2014

Aprovado em: 01/03/2014 